\title{
British white paper brings 'cultural change'
}

London. Research is being described in new terms at the Engineering and Physical Sciences Research Council (EPSRC), the largest of Britain's six research funding agencies. The council increasingly refers to university-based research groups as its "suppliers", and industry as its "customer base".

Alan Rudge - the chairman of the council, and former director of research at British Telecom - goes further, describing the council as similar to a board of directors, with responsibility for defining strategy and providing "sensible answers" to problems that the council faces.

The council's new thinking is representative of one of the most striking changes catalysed by the government's 1993 white paper (policy document), Realizing our Potential. (The council itself was created following a recommendation in the paper to break up the Science and Engineering Research Council (SERC).)

Government officials claim that this shift in self-perception is an important part of a cultural revolution, which they have sought to engineer through the changes outlined in the white paper. These emphasize using the science base to create wealth and - although in practice to a lesser extent - to improve quality of life.

The white paper has had less impact in other areas, however. The threat that the Medical Research Council's institutes might be sold or privatized, for example, has not materialized. The agency - which, observers point out, already works closely with industry and the health services to develop applications of its research - has been able to continue operating much as it did before.

The Particle Physics and Astronomy Research Council (PPARC) - which was also created from the break-up of SERC also continues to fund mainly basic research. It is under increasing political pressure, how- ever, to get better value from its subscriptions to international facilities (see Nature 372, 712; 1994).

Moreover, the government has dropped some of the most radical - and widely criticized - reforms proposed in the white paper. For example, the new one-year master's degree - billed as a cost-effective initiation in re-

search-willnot

be compulsory

for students wishing to apply for PhD programmes funded by the research councils, as previously proposed (see Nature 372, 7; 1994).

Similarly, the government is likely to shelve proposals to privatize many of its public research laboratories. A civil-service review intended to prepare for their sale has been criticized by almost all the bodies interested in the health of British science (see Nature 372, 718; 1994).

The outcome of the ambitious 'technology foresight' exercise, which the white paper proposed as the major channel of "user input' into government science policy, is more difficult to predict. Early fears that it would focus on narrow industrial goals have subsided, but many remain concerned that pressure from the Treasury for results from public investment in science could lead to emphasis on short-term thinking.

The view that the most important impact of the white paper has been to prompt an evolution in attitudes in the research community is also shared by Tom Blundell, chief executive of the Biotechnology and Biological Sciences Research Council

\section{Indian science turns to industry}

New Delhi. The past year in India has seen government laboratories being forced to turn increasingly to industry for support, because of reduced public funding. This, in turn, has put pressure on basic research which has given way to commercially exploitable applied research.

Another factor that has encouraged Indian scientists to commercialize their results is a new law allowing product patents in health, food and agriculture, following the signing last year of the General Agreement on Trade and Tariffs (GATT). The liberalization of economic policies has also helped to encourage commercialization of research results.
As evidence of this, India exported - or licensed or patented abroad - several technological products in 1994. "India is no longer just an importer of technology," says S. K. Joshi, secretary to the Department of Scientific and Industrial Research. "We have become a global player in some areas."

The research and development culture in industry is also changing because of the opening up of India to foreign technology and capital. In particular, drug companies are increasing investment; the New Delhibased company Ranbaxy Pharmaceuticals Ltd, for example, has set up a US\$5-million centre for drug research. K. S. Jayaraman
(BBSRC) - which combines the activities of the former Agricultural and Food Research Council with SERC's biological work - and professor of crystallography at Birkbeck College in London.

Blundell says that there has not been a shift from basic research to either strategic or applied research, as some had feared. The white paper, he argues, has helped to focus attention on the importance of basic science to long-term questions of wealth - and health - creation.

Both the EPSRC and the BBSRC are faced, to a far greater extent than the other research councils, with bridging the development gap between technologically conservative industries - for example, the agrofood industry - and the innovative potential of discoveries in basic science.

Both councils are also struggling to introduce new procedures for allocating research funds. Their aim is to adapt the best of former practices for selecting and assessing research grants to their new pressures and priorities. The consequent changes in the role and structure of the peer-review process will be a contentious issue over the coming months.

The most urgent task for both councils is to reconcile the government's demand to mould research more closely to national needs and reduce spending. Rudge says it is his council's responsibility to carry out the government's instructions as "efficiently and effectively as possible". Rudge considers final staff numbers as an "output of the way of doing things right".

A different view is taken by the Institution of Professionals, Managers and Specialists, the labour union that represents many government-funded scientists and science administrators. The union opposes cuts and argues that a sufficient critical mass of science expertise is needed to preserve a strong science base.

Events this year will help to clarify the impact of the white paper - in particular, the new research council structures will be put in place and the government will publish the first conclusions of the technology foresight exercise.

But conflict can also be expected as a result, for example, of the large staff cuts expected at the research councils and demands for greater cost-effectiveness in international programmes, such as those financed through the European Union's Framework programme, or the European Space Agency.

David Dickson

\section{Correction}

Lyle Bivens, director of the US Office of Research Integrity (ORI), was inadvertently referred to as "she" in a recent news story (Nature 372, 391; 1994) about the ORI's report on a paper by Thereza Imanishi-Kari. 